\title{
Is being malnourished according to the ESPEN definition for malnutrition associated with clinically relevant outcome measures in geriatric outpatients?
}

\author{
N. M. van Rijssen ${ }^{1,2}$ - A. G. M. Rojer ${ }^{2}$ - M. C. Trappenburg ${ }^{2,3}$ - E. M. Reijnierse ${ }^{4}$. C. G. M. Meskers ${ }^{5,6} \cdot$ A. B. Maier ${ }^{4,6}$. \\ M. A. E. de van der Schueren ${ }^{1,7}$
}

Received: 8 January 2018 / Accepted: 19 April 2018 / Published online: 3 May 2018

(c) The Author(s) 2018

\begin{abstract}
Background and aim A body of evidence is supporting the association between (the risk of) malnutrition in relation to physical performance, muscle strength, risk for depression and cognitive status in geriatric outpatients. Associations between being malnourished according to the newly proposed ESPEN definition for malnutrition and clinically relevant outcome measures of the aforementioned variables have not been confirmed yet. Therefore, the aim of this study was to examine the association between being malnourished according to the ESPEN definition and clinically relevant outcome measures in geriatric outpatients.

Methods Associations between malnutrition and handgrip strength (HGS, kg), short physical performance battery (SPPBscore, points), timed up and go test (TUG, seconds), and hospital anxiety and depression scale (HADS depression score, points), were analysed using linear regression. History of falls (falls, yes/no) and a low score on the Mini Mental-State Examination (MMSE-score $\leq 24$ points) were analysed using logistic regression. All analyses were adjusted for age and gender.

Results A total of 185 geriatric outpatients (60\% women) were included. The mean age was $82( \pm 7.3)$ years. Being malnourished (8.2\%) according to the ESPEN definition was significantly associated with a lower HGS $(-3.38 \mathrm{~kg}, p=0.031)$, lower SPPB score ( -1.8 point, $p=0.025)$, higher TUG time (1.35 times higher time, $p=0.020)$ and higher HADS depression score (2.03 times higher score, $p=0.007)$. Being malnourished tended towards an association with falls $(\mathrm{OR} 3.84, p=0.087)$. No significant association was found with low MMSE score (OR 2.61, $p=0.110$ ).

Conclusion This study is the first to confirm the association between being malnourished, defined by the ESPEN definition and clinically relevant outcome measures in geriatric outpatients.
\end{abstract}

Keywords Malnutrition $\cdot$ Nutrition $\cdot$ Physical performance $\cdot$ Muscle strength $\cdot$ Depression $\cdot$ Aged

M. A. E. de van der Schueren

m.devanderschueren@vumc.nl

1 Department of Internal Medicine, Section of Nutrition and Dietetics, VU University Medical Center, De Boelelaan 1118, Room ZH4A15, 1081 HV Amsterdam, The Netherlands

2 Department of Internal Medicine, Section of Gerontology and Geriatrics, VU University Medical Center, Amsterdam, The Netherlands

3 Department of Internal Medicine, Amstelland Hospital, Amstelveen, The Netherlands
4 Department of Medicine and Aged Care, Royal Melbourne Hospital, University of Melbourne, Melbourne, Australia

5 Department of Rehabilitation Medicine, VU University Medical Center, Amsterdam, The Netherlands

6 Department of Human Movement Sciences, MOVE Research Institute Amsterdam, Vrije Universiteit, Amsterdam, The Netherlands

7 Department of Nutrition, Sports and Health, Faculty of Health and Social Sciences, HAN University of Applied Sciences, Nijmegen, The Netherlands 


\section{Introduction}

The European Society for Clinical Nutrition and Metabolism (ESPEN) proposed a new consensus definition for malnutrition in 2015. In this definition, fat-free mass index (FFMI) was introduced as an additional parameter to determine malnutrition, as FFMI provides important information on functional reserves and metabolic processes [1].

This new ESPEN definition seems to identify less malnourished patients compared to other tools [2, 3]. In geriatric (out)patients, malnutrition has previously been associated with poorer clinical outcomes, such as impaired muscle strength, worse physical performance, depression or worse cognitive status [4-7]. Therefore, the aim of the present study is to study whether the new ESPEN definition confirms this previously described associations, now that FFMI has been added as additional parameter to the definition.

\section{Materials and methods}

\section{Study design}

In this cross-sectional cohort study, 185 geriatric outpatients who were included who referred to the geriatric outpatient clinic of the Bronovo Hospital (The Hague, the Netherlands) between March 2011 and January 2012. All patients underwent a comprehensive geriatric assessment. No exclusion criteria were applied. This study was reviewed and approved by the institutional review board of the Leiden University Medical Centre (Leiden, the Netherlands). Data were obtained during routine care and the need for individual informed consent was waived by the ethical review board.

\section{Geriatric outpatient characteristics}

Medical records were used to collect data on sex, age, polypharmacy (the use of five or more medicines) and multimorbidity (two or more of the following chronic diseases: hypertension, myocardial infarct, chronic obstructive pulmonary disease (COPD), Parkinson's disease, diabetes mellitus, cancer, rheumatoid arthritis, and osteoarthritis. Unintentional weight loss $(<3 \mathrm{~kg}$ weight loss vs. $\geq 3 \mathrm{~kg}$ weight loss), current alcohol use (yes/no) and falls (yes/no) in the past 12 months were self-reported. Body mass index (BMI, $\mathrm{kg} / \mathrm{m}^{2}$ ), fat-free mass (FFM, $\mathrm{kg}$ ) and fat-free mass index (FFM/height $\left.{ }^{2}\right)$ were derived from direct segmental multi-frequency bioelectrical impedance analysis (DSM-BIA; In-Body 720; Biospace Co., Ltd, Seoul, Korea). Due to a protocol amendment BIA measurements were added at a later stage and performed in 135 out of 185 outpatients.

\section{ESPEN definition for malnutrition}

After initial screening by a valid screening tool, the ESPEN definition comprises of two options to diagnose malnutrition [1]. The first option comprises a BMI below $18.5 \mathrm{~kg} /$ $\mathrm{m}^{2}$. The second option comprises unintentional weight loss ( $>10 \%$ indefinite of time, or $>5 \%$ over the last 3 months), combined with either a low BMI $\left(<20 \mathrm{~kg} / \mathrm{m}^{2}\right.$ if $<70$ years old or $<22 \mathrm{~kg} / \mathrm{m}^{2}$ if $\geq 70$ years old) or a low FFMI (female: $<15 \mathrm{~kg} / \mathrm{m}^{2}$, male: $<17 \mathrm{~kg} / \mathrm{m}^{2}$ ) [1]. Outpatients were diagnosed as malnourished (yes/no) if they fulfilled at least one of these options.

\section{Outcome measures}

Muscle strength, physical performance, risk for depression, falls and cognitive status were considered as clinically relevant outcome measures. Handgrip strength (HGS in kg) [8] was used to measure muscle strength. The short physical performance battery (SPPB, $0-12$ points) [9] and timed up and go (TUG, in seconds) [10] were used to measure physical performance. The Hospital Anxiety and Depression Scale (HADS depression score, 0-21 points, higher score indicating higher risk) [11], was used to measure the risk for depression. Falls in the past 12 months $(\mathrm{y} / \mathrm{n})$ indicated the presence of falls. The Mini Mental-State Examination Score (MMSE-score, 0-30, low score defined as <24) [12] was used to measure cognitive status. All measurements were performed according to standard operating procedures.

\section{Statistical analysis}

Continuous variables that were normally distributed are presented as mean and standard deviation. Skewed distributions are presented as median and interquartile range. The associations between being malnourished according to the ESPEN definition (independent variable) and HGS, SPPB-score, TUG and HADS depression score (dependent variables) were analysed using linear regression analysis. TUG and HADS were not normally distributed and were, therefore, log-transformed. After back transformation to normal, the interpretation should be interpreted as 'times higher/lower compared to normal' (proportional change).

Low MMSE score and falls (dependent variables) were analysed using logistic regression analysis. Age and sex were found to be confounders for the associations and thus included in the adjusted model. 
Sensitivity analyses were performed excluding the 50 patients without a measurement of FFMI.

Data were analysed using the Statistical Package for the Social Sciences 22.0 (SPSS Inc., Chicago, Illinois, USA). $p$-values below 0.05 were considered statistically significant. $p$-values below 0.10 were considered as tending towards an association.

\section{Results}

\section{Geriatric-outpatient characteristics}

Table 1 shows the characteristics of the geriatric outpatients. Eight percent $(n=14)$ of patients were diagnosed malnourished: two (1.1\%) had a BMI below $18.5 \mathrm{~kg} / \mathrm{m}^{2}, 11(5.9 \%)$ had experienced unintentional weight loss in combination with a low BMI, and nine (4.9\%) had experienced unintentional weight loss in combination with a low FFMI. Seven out of fourteen outpatients were malnourished according to more than one option of the ESPEN definition.

\section{Associations between the ESPEN definition for malnutrition and outcome measures}

Table 2 shows the results of the linear regression analyses for the association between being malnourished and HGS, SPPB score, TUG and HADS depression score.

Being malnourished was significantly associated with lower HGS, lower SPPB score, a higher TUG time and a higher score on the HADS depression score, after adjustments for age and sex. Malnourished outpatients had a $3.38 \mathrm{~kg}$ lower HGS $(p=0.031), 1.8$ points lower SPPB score $(p=0.025)$, a 1.35 times higher TUG time $(p=0.020)$, and a 2.03 times higher score on the HADS depression score $(p=0.007)$ compared to outpatients who were not malnourished.

Table 3 shows the results of the logistic regression analyses for the association between malnutrition, falls and low MMSE score. Malnutrition tended to be associated with falls; the odds on a fall was 3.84 higher $(p=0.087)$ compared to not being malnourished, adjusted for age and sex. No significant association between being malnourished and MMSE score was found.

In outpatients with available FFMI $(n=135)$, the associations between the ESPEN definition for malnutrition and clinically relevant outcome were almost identical to the results in the total population. The association with SPPB score slightly attenuated from a 1.814 lower SPPB score $(p=0.025)$ in the total population to a 1.523 point lower
Table 1 Geriatric outpatient characteristics

\begin{tabular}{|c|c|c|}
\hline & $N$ & All \\
\hline Age, years & 185 & $82.0(7.3)$ \\
\hline Female, $n(\%)$ & 185 & $111(60.0)$ \\
\hline Widowed, $n(\%)$ & 183 & $78(42.6)$ \\
\hline Living independent, $n(\%)$ & 145 & $59(40.7)$ \\
\hline \multicolumn{3}{|l|}{ Anthropometry } \\
\hline Height, $(\mathrm{cm})$ & 177 & $167.1(9.9)$ \\
\hline Weight (kg) & 173 & $71.9(15.6)$ \\
\hline $\mathrm{BMI}\left(\mathrm{kg} / \mathrm{m}^{2}\right)$ & 171 & $25.7(4.4)$ \\
\hline FFMI $\left(\mathrm{kg} / \mathrm{m}^{2}\right)$ & 135 & $17.3(2.8)$ \\
\hline Male & 55 & $18.7(2.8)$ \\
\hline Female & 80 & $16.4(2.4)$ \\
\hline \multicolumn{3}{|l|}{ Parameters of health } \\
\hline Unintentional weight loss, $n(\%)$ & 185 & $24(13)$ \\
\hline Polypharmacy, $n(\%)^{\mathrm{a}}$ & 180 & $110(61.1)$ \\
\hline Multimorbidity, $n(\%)^{\mathrm{b}}$ & 177 & $67(37.9)$ \\
\hline Current alcohol use, $n(\%)$ & 185 & $74(40)$ \\
\hline \multicolumn{3}{|l|}{ ESPEN definition for malnutrition } \\
\hline Malnourished, $n(\%)$ & 171 & $14(8.2)$ \\
\hline $\mathrm{BMI}<18.5\left(\mathrm{~kg} / \mathrm{m}^{2}\right)$ & & $2(1.1)$ \\
\hline Unintentional weight loss + low BMI & & $11(5.9)$ \\
\hline Unintentional weight loss + low FFMI & & $9(4.9)$ \\
\hline \multicolumn{3}{|l|}{ Clinically relevant outcome measures } \\
\hline Handgrip strength, (kg) & 181 & $26.1(8.4)$ \\
\hline Male & 73 & $33.9(6.1)$ \\
\hline Female & 108 & $20.8(5.0)$ \\
\hline SPPB score & 179 & $7.0(3.4)$ \\
\hline TUG, seconds, median [IQR] & 160 & $15.8[11.8-21.8]$ \\
\hline HADS depression score, median [IQR] & 115 & $5.0[3-9]$ \\
\hline Falls in the past 12 months, $n(\%)$ & 185 & $118(63.8)$ \\
\hline Low MMSE score, $n(\%)^{\mathrm{c}}$ & 183 & $40(21.9)$ \\
\hline
\end{tabular}

All numbers are presented as mean (SD) unless indicated otherwise

$B M I$ body mass index, FFMI fat-free mass index, ESPEN European Society for Clinical Nutrition and Metabolism, $S P P B$ short physical performance battery, $T U G$ timed up and go test, $I Q R$ interquartile range, HADS Hospital and Anxiety Scale, MMSE mini-mental state examination

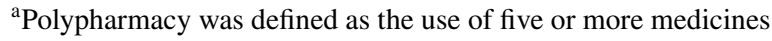

${ }^{b}$ Multimorbidity was defined as two or more of following chronic diseases: hypertension, myocardial infarct, COPD, cancer, diabetes mellitus, rheumatoid arthritis, osteoarthritis, Parkinson's disease

${ }^{\mathrm{c}}$ Low MMSE-score is defined as a MMSE-score $<24$

SPPB score $(p=0.074)$ in the outpatients with FFMI available. The association with low MMSE score changed from a 2.614 higher odds $(p=0.110)$ on a low MMSE score in the total population into a 3.934 higher odds $(p=0.033)$ on a low MMSE score in outpatients with FFMI available. 


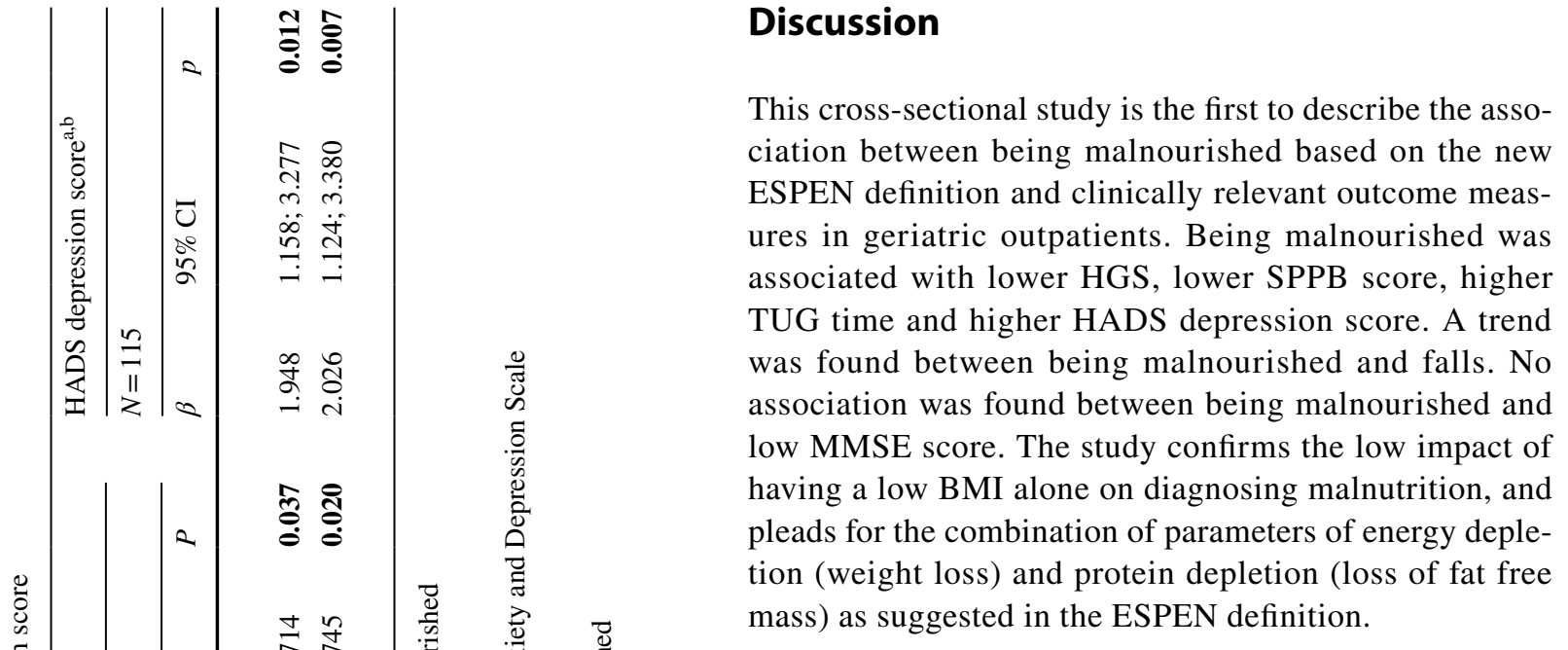

\section{Geriatric outpatient population}

The prevalence of malnutrition according to the ESPEN definition in this study $(8.2 \%)$ is in line with a recently published meta-analysis by Cereda et al. using the full Mini Nutritional Assessment (MNA) in geriatric outpatients (6.4\%) [2]. Our study also confirms the previously reported associations between (the risk of) malnutrition (mostly defined by MNA) and HGS, SPPB score, TUG and HADS depression score $[4-6,13]$.

In the present study, a trend was observed for the association between being malnourished and falls. This is in discrepancy with a study of van Bokhorst de van der Schueren et al. [6] where falls were recalled differently as ever versus never and the present study reported a fall (yes/no) in the past 12 months.

In the present study, no association was found between being malnourished and a low MMSE score which is in line with previous studies $[6,14]$ in a population of geriatric patients.

In previous studies, the terms "malnutrition" and "risk of malnutrition" were often used interchangeably, leading to higher prevalence rates of malnutrition. The variety of settings in which studies were performed may also explain the different prevalence rates and different associations between malnutrition and outcome measures.

\section{Strengths and limitations}

This study is the first to describe the association between the new ESPEN criteria for malnutrition and clinically relevant outcome measures. In addition, the clinically relevant outcome measures that were used were measured objectively, except for falls and HADS, which were obtained by questionnaires. 
Table 3 Associations between being malnourished according to the ESPEN definition and falls and low MMSE score

\begin{tabular}{|c|c|c|c|c|c|c|}
\hline & \multicolumn{3}{|l|}{ Falls } & \multicolumn{3}{|c|}{ Low MMSE score } \\
\hline & \multicolumn{3}{|c|}{$N=171$} & \multicolumn{3}{|c|}{$N=169$} \\
\hline & OR & $95 \% \mathrm{CI}$ & $p$ & OR & $95 \% \mathrm{CI}$ & $p$ \\
\hline \multicolumn{7}{|l|}{ Malnourished } \\
\hline Crude model & 3.916 & $0.847 ; 18.098$ & 0.081 & 2.520 & $0.784 ; 8.097$ & 0.121 \\
\hline $\begin{array}{l}\text { Model } 1 \text { (age and } \\
\text { sex adjusted) }\end{array}$ & 3.841 & $0.822 ; 17.958$ & 0.087 & 2.614 & $0.806 ; 8.482$ & 0.110 \\
\hline
\end{tabular}

Interpretation: malnourished outpatients have a 3.84 higher odds $(\mathrm{p}=0.087)$ on a fall in the past 12 months compared to outpatients who were not malnourished (not significant)

Low MMSE score is defined as a MMSE-score $<24$

$C I$ confidence interval, $O R$ odds ratio, MMSE mini-mental state examination
A limitation of this study is the small sample of malnourished outpatients. The low prevalence might be a definition problem: if the definition is too strict, the prevalence will always be low. Another problem might be that geriatric outpatients are often at risk for malnutrition instead of being diagnosed as malnourished; until now the ESPEN definition does not have a category for at-risk patients. Furthermore, the complexity of diagnosing malnutrition is a limitation; for example cognitive impairment, depression or falls may be risk factors as well as outcome factors. A final limitation is that a small inter-observer variability could have occurred, although standard operating procedures were applied.

\section{Conclusion}

This study is the first to confirm the association between being malnourished, defined by the new ESPEN definition, and clinically relevant outcome measures in a population of geriatric outpatients. Future research should focus on determining the predictive value of the ESPEN definition and thereby taking the different cut off points used into account.

Acknowledgements The authors thank M. Stijntjes and J.H. Pasma for their contribution to the study. NMvR, AGMR, EMR, MCT, ABM, CGMM and MAEdvdS designed the study. NMvR performed the data analysis and drafted the manuscript. All authors contributed to the writing of the manuscript. All authors approved the final version of the manuscript.

Funding This study was supported by the seventh framework program MYOAGE (HEALTH-2007-2.4.5-10), by the Dutch Technology Foundation STW, which is part of the Netherlands Organization for Scientific Research, and by the European Union's Horizon 2020 research and innovation programme (Nos. 689238 and 675003).

\section{Compliance with ethical standards}

Conflict of interest The authors declare that they have no conflict of interest.

Ethical approval The study was reviewed and approved by the institutional review board (IRB) of the Leiden University Medical Center (Leiden, the Netherlands). Ethical guidelines were followed in accordance with the Declaration of Helsinki.

Informed consent This research is based on regular care, the need for individual informed consent was waived by the aforementioned IRB.

Open Access This article is distributed under the terms of the Creative Commons Attribution 4.0 International License (http://creativeco mmons.org/licenses/by/4.0/), which permits unrestricted use, distribution, and reproduction in any medium, provided you give appropriate credit to the original author(s) and the source, provide a link to the Creative Commons license, and indicate if changes were made.

\section{References}

1. Cederholm T, Bosaeus I, Barazzoni R, Bauer J, Van Gossum A, Klek S, Muscaritoli M, Nyulasi I, Ockenga J (2015) Diagnostic criteria for malnutrition-An ESPEN consensus statement. Clin Nutr 34(3):335-340. https://doi.org/10.1016/j.clnu.2015.03.001

2. Cereda E, Pedrolli C, Klersy C, Bonardi C, Quarleri L, Cappello S, Turri A, Rondanelli M, Caccialanza R (2016) Nutritional status in older persons according to healthcare setting: a systematic review and meta-analysis of prevalence data using MNA(R). Clin Nutr 35(6):1282-1290. https://doi.org/10.1016/j. clnu.2016.03.008

3. Schilp J, Kruizenga HM, Wijnhoven HA, Leistra E, Evers AM, van Binsbergen JJ, Deeg DJ, Visser M (2012) High prevalence of undernutrition in Dutch community-dwelling older individuals. Nutrition 28(11-12):1151-1156. https://doi.org/10.1016/j. nut.2012.02.016

4. Singh DK, Manaf ZA, Yusoff NA, Muhammad NA, Phan MF, Shahar S (2014) Correlation between nutritional status and comprehensive physical performance measures among older adults with undernourishment in residential institutions. Clin Interv Aging 9:1415-1423. https://doi.org/10.2147/CIA.S64997

5. Yoshimura K, Yamada M, Kajiwara Y, Nishiguchi S, Aoyama $\mathrm{T}$ (2013) Relationship between depression and risk of malnutrition among community-dwelling young-old and old-old 
elderly people. Aging Mental Health 17(4):456-460. https://doi. org/10.1080/13607863.2012.743961

6. van Bokhorst-de van der Schueren MA, Lonterman-Monasch S, de Vries OJ, Danner SA, Kramer MH, Muller M (2013) Prevalence and determinants for malnutrition in geriatric outpatients. Clin Nutr 32(6):1007-1011. https://doi.org/10.1016/j.clnu.2013.05.007

7. Aartolahti E, Hartikainen S, Lonnroos E, Hakkinen A (2014) Health and physical function predicting strength and balance training adoption: a community-based study among individuals aged 75 and older. J Aging Phys Act 22(4):543-549. https://doi. org/10.1123/japa.2013-0113

8. Reijnierse EM, Trappenburg MC, Leter MJ, Blauw GJ, de van der Schueren MA, Meskers CG, Maier AB (2015) The association between parameters of malnutrition and diagnostic measures of sarcopenia in geriatric outpatients. PLoS ONE 10(8):e0135933. https://doi.org/10.1371/journal.pone.0135933

9. Guralnik JM, Simonsick EM, Ferrucci L, Glynn RJ, Berkman LF, Blazer DG, Scherr PA, Wallace RB (1994) A short physical performance battery assessing lower extremity function: association with self-reported disability and prediction of mortality and nursing home admission. J Gerontol 49(2):M85-M94

10. Podsiadlo D, Richardson S (1991) The timed "Up \& Go": a test of basic functional mobility for frail elderly persons. J Am Geriatr Soc 39(2): 142-148

11. Zigmond AS, Snaith RP (1983) The hospital anxiety and depression scale. Acta Psychiatr Scand 67(6):361-370

12. Folstein MF, Folstein SE, McHugh PR (1975) "Mini-mental state": a practical method for grading the cognitive state of patients for the clinician. J Psychiatr Res 12(3):189-198

13. Norman K, Stobaus N, Gonzalez MC, Schulzke JD, Pirlich M (2011) Hand grip strength: outcome predictor and marker of nutritional status. Clin Nutr 30(2):135-142. https://doi.org/10.1016/j. clnu.2010.09.010

14. Isenring E, Baker J, Kerr G (2013) Malnutrition and falls risk in community-dwelling older adults. J Nutr Health Aging 17(3):277279. https://doi.org/10.1007/s12603-012-0408-2 